\title{
New mechanistic insights of integrin $\beta 1$ in breast cancer bone colonization
}

\author{
Laure Thibaudeau ${ }^{1, *}$, Anna V. Taubenberger ${ }^{1,2, *}{ }^{,}$Christina Theodoropoulos ${ }^{1}$, Boris \\ M. Holzapfel ${ }^{1,3}$, Olivier Ramuz ${ }^{4}$, Melanie Straub ${ }^{5}$ and Dietmar W. Hutmacher ${ }^{1,6,7}$ \\ ${ }^{1}$ Institute of Health and Biomedical Innovation, Queensland University of Technology, Kelvin Grove, QLD, Brisbane, Australia \\ 2 TU Dresden, Biotechnology Center, Tatzberg, Dresden, Germany \\ ${ }^{3}$ Orthopedic Center for Musculoskeletal Research, University of Wuerzburg, Brettreichstraße, Wuerzburg, Germany \\ ${ }^{4}$ Department of Anatomical Pathology and Cytopathology, Pathology Queensland Central Laboratory, Royal Brisbane and \\ Women's Hospital, Herston QLD, Australia \\ ${ }^{5}$ Institute of Pathology, University Clinic Rechts der Isar, Technical University Munich, Trogerstr, Munich, Germany \\ ${ }^{6}$ George W Woodruff School of Mechanical Engineering, Georgia Institute of Technology, Atlanta, GA, United States of \\ America \\ ${ }^{7}$ Institute for Advanced Study, Technical University Munich, Lichtenbergstraße, Garching, Germany \\ * These authors contributed equally to this work
}

Correspondence to: Dietmar W. Hutmacher, email: dietmar.hutmacher@qut.edu.au

Keywords: bone colonization, breast cancer, $\beta 1$ integrin, humanized bone models, tissue engineering

Received: November 04, $2014 \quad$ Accepted: November 14, $2014 \quad$ Published: November 15, 2014

This is an open-access article distributed under the terms of the Creative Commons Attribution License, which permits unrestricted use, distribution, and reproduction in any medium, provided the original author and source are credited.

\section{ABSTRACT}

Bone metastasis is a frequent and life-threatening complication of breast cancer. The molecular mechanisms supporting the establishment of breast cancer cells in the skeleton are still not fully understood, which may be attributed to the lack of suitable models that interrogate interactions between human breast cancer cells and the bone microenvironment. Although it is well-known that integrins mediate adhesion of malignant cells to bone extracellular matrix, their role during bone colonization remains unclear. Here, the role of $\beta 1$ integrins in bone colonization was investigated using tissue-engineered humanized in vitro and in vivo bone models. In vitro, bonemetastatic breast cancer cells with suppressed integrin $\beta 1$ expression showed reduced attachment, spreading, and migration within human bone matrix compared to control cells. Cell proliferation in vitro was not affected by $\beta 1$ integrin knockdown, yet tumor growth in vivo within humanized bone microenvironments was significantly inhibited upon $\beta 1$ integrin suppression, as revealed by quantitative in/ex vivo fluorescence imaging and histological analysis. Tumor cells invaded bone marrow spaces in the humanized bone and formed osteolytic lesions; osteoclastic bone resorption was, however, not reduced by $\beta 1$ integrin knockdown. Taken together, we demonstrate that $\beta 1$ integrins have a pivotal role in bone colonization using unique tissue-engineered humanized bone models.

\section{INTRODUCTION}

Breast cancer (BC) is the most commonly diagnosed cancer and the second cancer-related cause of death in women in the western world [1-3]. Due to improved screening methods and treatments strategies, the mortality rate from this disease has decreased significantly over the last decades [1-3]. However, BC patients who appear in complete clinical remission may already have dormant disseminated tumor cells present at secondary sites in the skeleton, lung, liver or brain, which can result in late recurrence and the development of metastases. The appearance of overt bone metastases marks the entrance into an incurable phase of the disease, as the currently 
available treatment options are rather palliative than providing a cure $[4,5]$. Therefore, the mechanisms by which $\mathrm{BC}$ cells home to the skeleton and colonize the bone microenvironment need to be better understood.

During the process of dissemination from the primary tumor to bone, $\mathrm{BC}$ cells adhere to and communicate with the surrounding tissues. Once BC cells have reached the metastatic bone site, they interact with their new microenvironment, which comprises bone matrix and different bone-resident cells. Among other cell adhesion molecules, integrins are known to mediate cellular interactions between tumor cells and the bone matrix $[6,7]$. Integrins play important roles in the development and progression of cancers, and several integrins have been shown to be overexpressed in different types of cancer $[8,9]$. In the case of $\mathrm{BC}$, integrins $\beta 1$ and $\beta 3$ expressed on tumor cells play major roles, not only during tumor development and invasion, but also during cancer cell homing and the establishment of metastatic lesions $[10,11]$. For instance, $\beta 1$ integrin expression in $\mathrm{BC}$ cells is necessary for the initiation and maintenance of tumor growth in mice [12-14] and promotes metastasis from the primary site $[13,15,16]$. It has been demonstrated that treatment with ATN-161, a fibronectin-derived peptide known to interfere with integrin $\alpha 5 \beta 1$ and $\alpha v \beta 3$ binding, resulted in a marked decrease in the incidence and number of skeletal and soft tissue metastases after intracardiac injection of MDA-MB-231 BC cells in nude mice, suggesting also a possible role for these integrin heterodimers in BC osteotropism [17].

So far $\alpha v \beta 3$ integrin has been the focus of most studies looking at factors involved in bone metastasis. For instance, various in vivo experiments have suggested that $\alpha v \beta 3$ integrin increases the potential of human and murine $\mathrm{BC}$ cell lines to form bone metastases [18-20]. In addition, injection of murine mammary tumor cells (66cl4) that overexpressed integrin $\beta 3$ into the tibia of syngeneic mice resulted in increased osteoclast recruitment and bone resorption compared to parental cells [19]. It was also shown that treatment with the integrin inhibitor cilengitide or a snake venom-derived disintegrin (trigramin), both targeting primarily integrin $\alpha v \beta 3$, significantly reduced the volume of tumors in the bone and the extent of osteolytic lesions after BC cell injection into the hind leg of rodents [21, 22]. However, it still remains unclear whether $\alpha v \beta 3$ integrins specifically influence bone colonization or rather the prior arrest of $\mathrm{BC}$ cell in the skeleton. In fact, mice treated with the selective $\alpha v \beta 3$ inhibitor S247 presented a reduced incidence and size of osteolytic lesions only when it was administered prior to the intracardiac inoculation of MDA-MB-435 BC cells, while it did not have an effect on bone degradation after the tumor cells had already disseminated to the bone [23]. Similarly Zhao et al. observed that $\alpha \mathrm{v} \beta 3$-overexpressing MDA-MB-231 cells led to an increased skeletal tumor burden and bone destruction compared to control cells after intravenous inoculation, but not when the cells were injected directly into the tibial cavity [20]. Moreover, tumor cell proliferation in the bone microenvironment does not appear to be modulated by $\alpha v \beta 3$ [19], thus suggesting that other factors might play an important role in the establishment of $\mathrm{BC}$ cells in bone.

Despite their known role in primary tumor progression and their identification as a prognostic marker of invasive $\mathrm{BC}[24,25]$, to date very few studies have specifically investigated the role of $\beta 1$ integrins in $\mathrm{BC}$ induced bone colonization. In our previous work, we have used primary human osteoblastic cell-derived matrices (hOBM) as a model system to study human speciesspecific interactions occurring between bone-metastatic cancer cells and the bone matrix in vitro $[26,27]$. We have thereby shown that $\beta 1$ integrins mediate adhesion of metastatic $\mathrm{BC}$ cell lines to bone extracellular matrix (ECM) [27], as was also reported by others [28, 29]. In this work we hypothesized that humanized in vitro $[26,27]$ and in vivo models [30-32] will allow to dissect the role of $\beta 1$ integrins during bone colonization by metastatic BC cells. In our previous work, we have shown that human tissue-engineered bone constructs (hTEBCs) recapitulate a physiological "organ" bone with human-derived components and serve as a metastatic site for human BC cells in a murine host [30]. In the presented work we show that $\beta 1$ integrin knockdown reduces spreading, attachment, and migration of metastatic BC cells on hOBM in vitro. While no effect was seen on cell proliferation in vitro, a delayed onset and a significantly reduced rate of tumor growth was observed in vivo upon suppression of $\beta 1$ integrin expression. Despite their role in modulating tumor cell proliferation in the bone, $\beta 1$ integrins did not appear to influence osteoclast activation and bone resorption. Finally, using tissue-engineered bone microenvironments we demonstrate key roles of $\beta 1$ integrins during bone colonization of $\mathrm{BC}$ cells, thus suggesting that $\beta 1$ integrins are promising targets in the treatment of bone metastatic disease.

\section{RESULTS}

\section{$\beta 1$ integrins mediate $\mathrm{BC}$ cell interactions with hOBM}

In this study, we firstly investigated $\beta 1$ integrindependent interactions of $\mathrm{BC}$ cells with human bone matrices in vitro, comparing sets of $\mathrm{BC}$ cells expressing endogenous $\beta 1$ integrin and respective $\beta 1$ knockdown cells. hOBM were derived from primary human osteoblastic cells (hOBs) as previously characterized [26, 27]. Two invasive BC cell lines, MDA-MB-231 and its bone-metastatic subline, MDA-MB-231BO [33], were chosen. MDA-MB-231BO cells were initially generated 
by Yoneda et al. through repeated in vivo passaging in mice by intracardiac injection and isolation from metastases in the skeleton [33]. Both cell lines were either transduced with control (ctrKD) or $\beta 1$ integrintargeting $(\beta 1 \mathrm{KD})$ lentiviral shRNA vectors conjugated to green fluorescent protein (GFP). An efficient decrease in $\beta 1 \mathrm{mRNA}$ and protein (cell surface and total) levels was confirmed using quantitative real-time polymerase chain reaction (qRT-PCR), flow cytometry, and western blots (Supplementary Figure 1). GFP signals were comparable between ctrKD and $\beta 1 \mathrm{KD}$ cells as demonstrated by flow cytometry. Firstly, the spreading morphology of individual ctrKD and $\beta 1 \mathrm{KD}$ BC cells on tissue-culture plastic (TCP) and hOBM was characterized (Figure 1A). Consistent with our previous work [27], we observed that all cell types underwent significant morphological changes when seeded onto hOBM; while more randomly oriented on TCP, they aligned their major axes parallel to each other on hOBM. Confocal laser scanning microscopy images revealed that $\mathrm{BC}$ cells aligned along the bone matrix
A
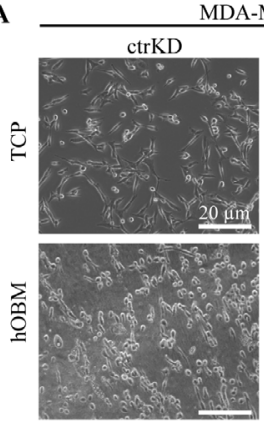

B
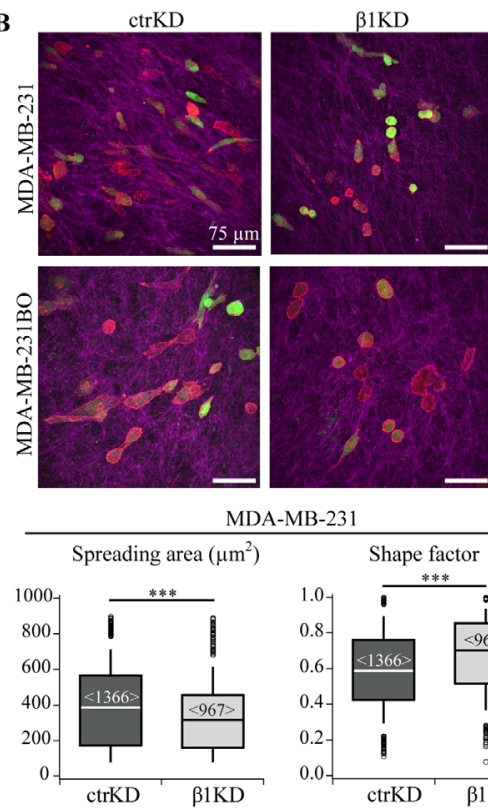

MDA-MB-23

C

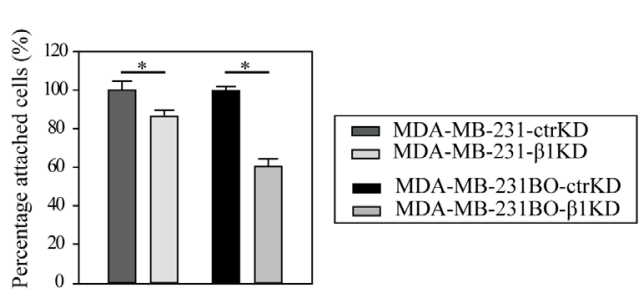

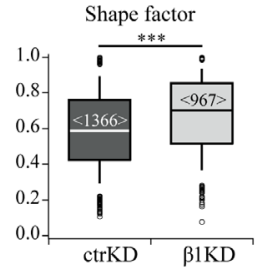

MDA-MB-231BO
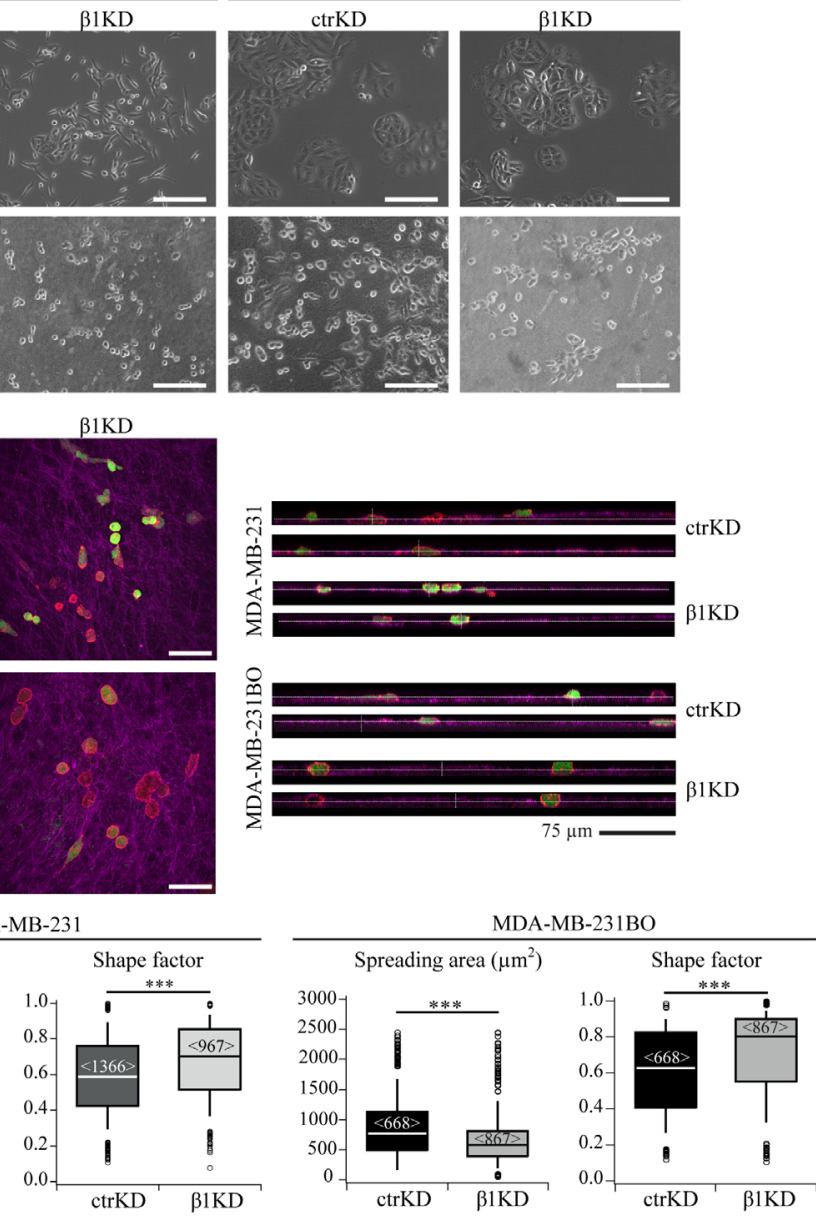

Figure 1: $\beta 1$ integrins mediate $\mathrm{BC}$ cell spreading and attachment in a human-bone like microenvironment in vitro. A: Representative phase contrast micrographs showing the morphology of ctrKD and $\beta 1 \mathrm{KD}$ BC cells grown on TCP and hOBM. B: Representative confocal z-stacks (maximal projections and orthogonal views) showing the morphology of GFP-positive (green) ctrKD and $\beta 1 \mathrm{KD}$ BC cells stained for F-actin (red) adhering for 24 hours on hOBM, which is visualized by an immunofluorescence staining against human-specific fibronectin (pink). Quantitative analysis of cell spreading area and shape factor. Box-plots show the medians, 75th and 25th percentiles; upper and lower whiskers indicate the 90th and 10th percentiles; circles denote outliers. Number of analyzed cells (from 6 different micrographs) is indicated in brackets. C: Quantification of cell attachment to hOBM. DNA content is measured after a 30 minutes attachment period and washing the cell layers. Data are represented as mean \pm standard error. 
fibers that were visualized using an immunofluorescent staining against human-specific fibronectin (Figure 1B). While the overall morphology of ctrKD and $\beta 1 \mathrm{KD}$ cells appeared similar on TCP (Figure 1A), quantitative image analysis demonstrated that $\beta 1 \mathrm{KD}$ cells were significantly less spread, and adopted a more rounded shape on hOBM compared to ctrKD cells (Figure 1B). Orthogonal views of the stained hOBM further indicated that a large proportion of both ctrKD and $\beta 1 \mathrm{KD}$ cells invaded and were partly embedded within the matrix (Figure 1B). To assess the effect of $\beta 1$ integrins on cell attachment to hOBM, washing assays were performed. After an attachment period of 30 minutes, a higher percentage of ctrKD cells remained attached to hOBM after washing compared to $\beta 1 \mathrm{KD}$ cells (Figure 1C). Similar effects of $\beta 1$ integrin knockdown on cell attachment were also observed using an additional BC cell line, SUM1315 (Supplementary Figure 2).

\section{$\beta 1$ integrins enhance BC cell migration on hOBM but have no effect on $\mathrm{BC}$ cell proliferation in vitro}

Next we assessed the effect of $\beta 1$ integrin knockdown on $\mathrm{BC}$ cell migration on hOBM. For both

cell lines, when compared to $\beta 1 \mathrm{KD}$ cells, ctrKD cells displayed an increased instantaneous migration speed on hOBM, while the directionality of cell movement was not affected (Figure 2A). In contrast, $\beta 1$ integrin knockdown had no significant effect on $\mathrm{BC}$ cell migration when cells were seeded onto intact (i.e., non-decellularized) hOB cultures, which may be attributed to integrin-independent cell-cell interactions between $\mathrm{BC}$ cells and hOBs, or the reduced $\mathrm{BC}$ cell-bone ECM contacts in the presence of a dense cell layer (Supplementary Figure 3). Since focal adhesion kinase (FAK) and extracellular signalregulated kinase (ERK) have been previously implicated in regulating cellular signaling pathways controlling cell migration, proliferation and survival [34-36], we analyzed phosphorylation of ERK1/2 and FAK using quantitative western blot analysis (Figure 2B, Supplementary Figure 4). In accordance with our previous study, ERK and FAK phosphorylation levels were increased on hOBM compared to TCP [27]. However, no changes in the phosphorylation levels of these signaling proteins were observed upon $\beta 1$ integrin knockdown. In addition, similar proliferation rates were observed for ctrKD and $\beta 1 \mathrm{KD}$ cells grown on TCP or on hOBM (Figure $2 \mathrm{C}$, Supplementary Figure 2). Similarly, ctrKD and $\beta 1 \mathrm{KD}$
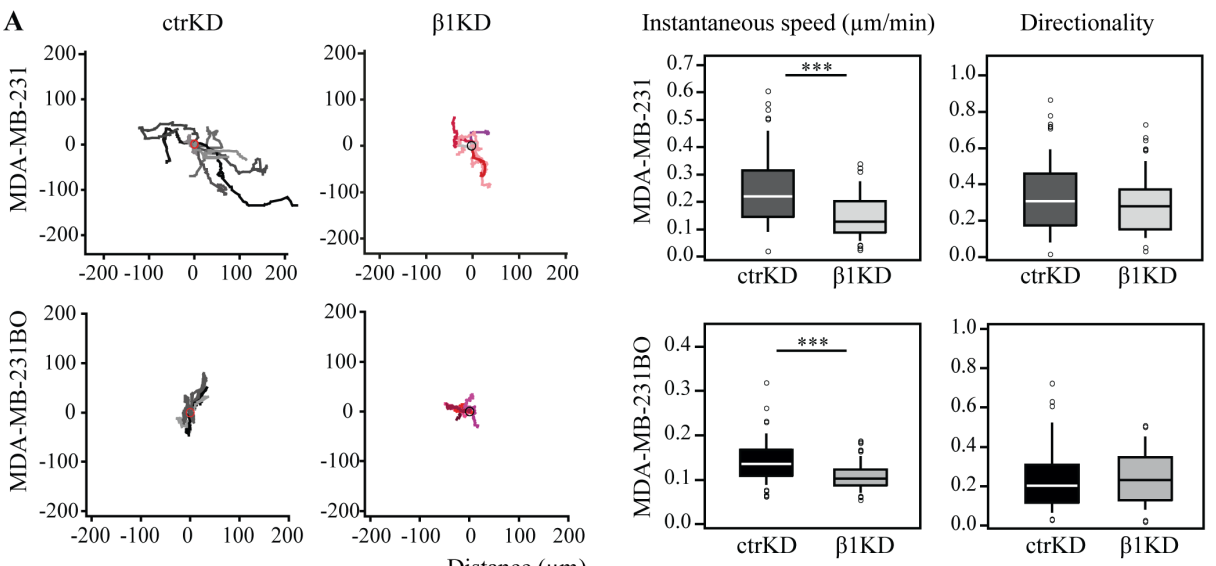

B
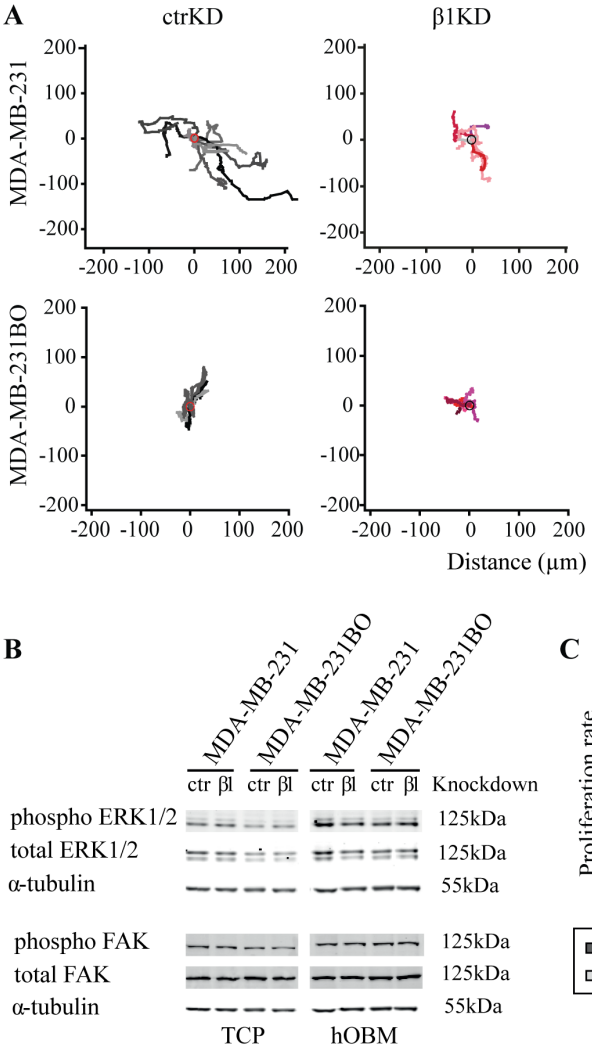

C

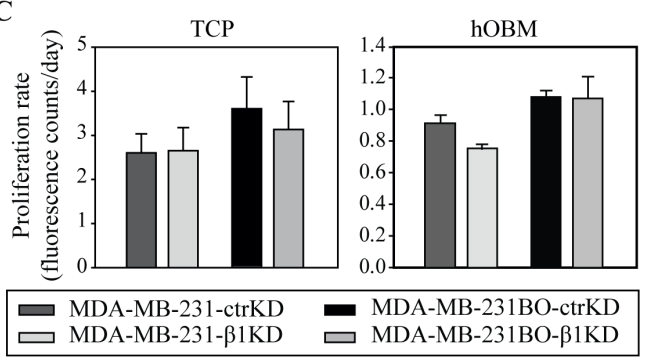

Figure 2: $\beta 1$ integrins promote BC cell migration on hOBM but have no effect on ERK/FAK cell signaling and proliferation in vitro. A: Representative tracks showing BC cell movement on hOBM and quantification of instantaneous migrational speed and directionality. Box-plots show the medians, 75th and 25th percentiles; upper and lower whiskers indicate the 90th and 10th percentiles; circles denote outliers. B: Western blot analysis of ERK1/2 and FAK phosphorylation in BC cells cultured on TCP and hOBM. C: Cell proliferation rates on TCP and hOBM evaluated by an Alamar Blue assay. Data are represented as mean \pm standard error. 
cells grown in three-dimensional (3D) in vitro cultures, embedded into a gelatin-based hydrogel of a stiffness of $3.4 \mathrm{kPa}$, did not show any differences in cell proliferation rates nor in colony size of 3D spheroids (Supplementary Figure 5).

\section{B1 integrins promote tumor growth in the humanized bone microenvironment in vivo}

We then sought to investigate the impact of $\beta 1$ integrin knockdown on bone colonization using a humanized engineered bone model that has been recently established for the study of different steps of metastasis of osteotropic cancers [30-32]. Given their high predilection to form bone metastases in mice, MDA-MB-231BO ctrKD and $\beta 1 \mathrm{KD}$ were used. As shown earlier, MDAMB-231BO cells are more successful in homing to and forming osteolytic lesions in the hTEBC than parental MDA-MB-231 cells [30]. To replicate a humanized bone microenvironment in mice, hOB-seeded scaffolds were implanted s.c. into the flanks of non-obese diabetic/ severe combined immunodeficient (NOD/SCID) mice in combination with bone morphogenetic protein 7 (BMP7). After 14 weeks, during which bone formation occurred and was verified by X-ray imaging (not shown), $1 \times 10^{6}$ MDA-MB-231BO ctrKD or $\beta 1 \mathrm{KD}$ BC cells were injected into the center of the hTEBCs (Figure 3A). Development of GFP-positive tumors was monitored weekly by in vivo fluorescent imaging from week 2 onwards. A significantly increased fluorescence signal was detected for all analyzed time points for ctrKD cells compared to $\beta 1 \mathrm{KD}$ cells (Figure 3B). Furthermore, tumor growth was delayed until three weeks post-injection for $\beta 1 \mathrm{KD}$ injected constructs, while GFP signals of ctrKD tumors were firstly detected at week 2 (Figure 3B). At the 4-week endpoint of the experiment, tumors and scaffolds were excised, imaged ex vivo, and measured in size using calipers. GFP signals could be detected in all specimens from both ctrKD and $\beta 1 \mathrm{KD}$ groups ex vivo, which may be attributed to the attenuation of the fluorescence signal when imaging in
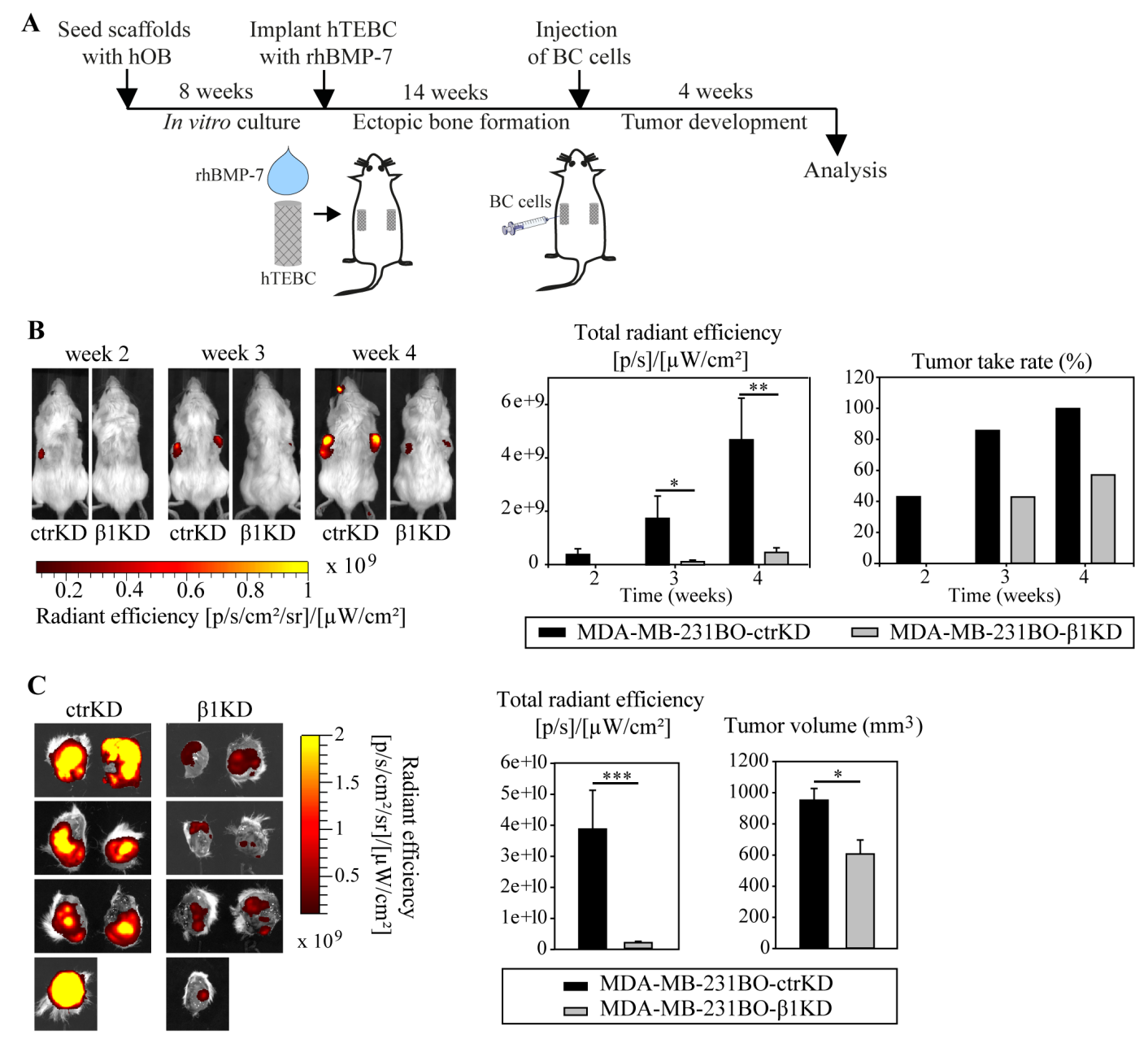

Figure 3: $\beta 1$ integrins promote the development of larger GFP-expressing tumors in the bone microenvironment in vivo. A: Schematic overview of the in vivo bone colonization experiment using the hTEBC model. B: Representative images and quantification of in vivo whole-body fluorescent imaging data over time. C: Images and quantification of ex vivo fluorescent imaging data at the experimental endpoint. Caliper measurements of tumor volume after excision. Data are represented as mean \pm standard error. 
vivo through the skin. However, consistent with the in vivo imaging data, significantly increased fluorescent signals together with larger tumors were observed in the control group compared to the group injected with $\beta 1 \mathrm{KD}$ cells (Figure 3C). qRT-PCR analysis revealed that $\beta 1$ integrin levels in tumors formed in $\beta 1 \mathrm{KD}$ cell-injected scaffolds remained significantly decreased after 4 weeks in vivo (Supplementary Figure 6A), while GFP levels stayed constant in tumors from both groups, as confirmed by quantitative immunohistochemistry (IHC) analysis (Supplementary Figure 6B).

In line with the imaging results, histological analysis on hematoxylin and eosin (H\&E)-stained sections from the tumor/hTEBC explants showed that tumor areas were larger in the ctrKD group (Figure 4A). Necrosis was seen mainly in the center of the larger tumors and, consistently with increased tumor sizes, increased necrotic areas were also observed in the ctrKD group. The tumors from both cell groups occupied most of the inside, and also grew outside of the engineered bone. The human origin of the tumor cells was demonstrated using IHC staining with a human nuclear mitotic apparatus protein (NuMA)specific antibody (Figure 4A). Using IHC analysis of cell proliferation based on the $\mathrm{Ki} 67$ marker, it was demonstrated that $\mathrm{BC}$ cells with $\beta 1$ integrin knockdown proliferated significantly less compared to controls (Figure 4B, Supplementary Figure 7). However no significant differences in tumor cell apoptosis and tumor vascularization could be detected (Figure 4C,D).

\section{$\beta 1$ integrins do not modulate $\mathrm{BC}$-induced bone resorption}

We next assessed whether knockdown of $\beta 1$ integrins influenced $\mathrm{BC}$-induced osteolysis. Ex vivo
A
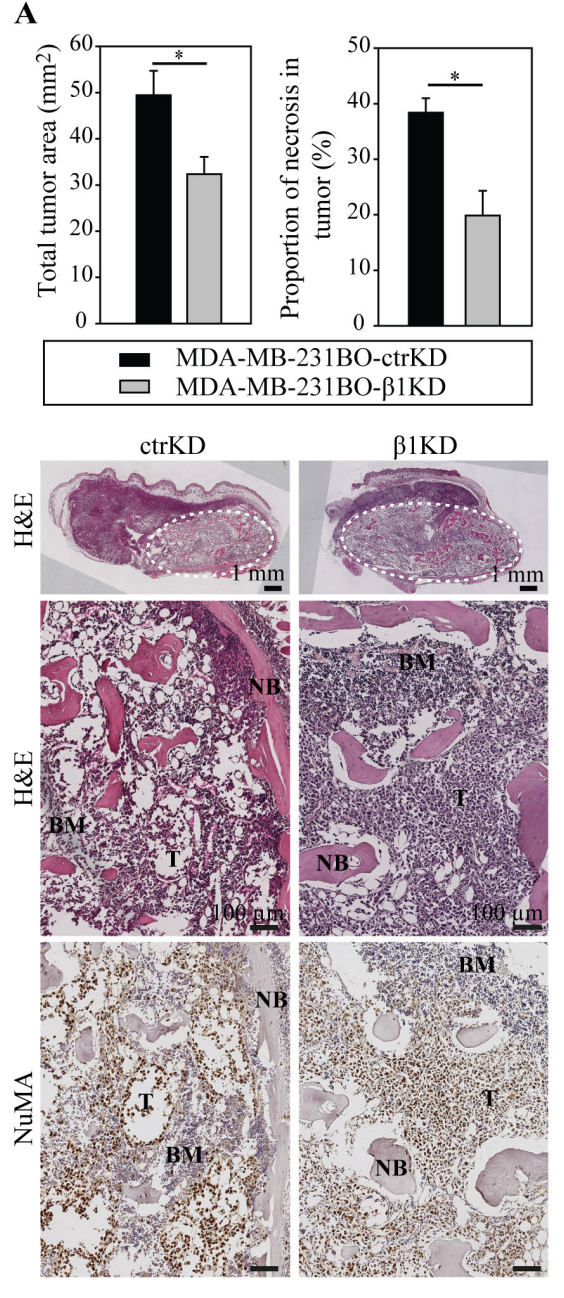
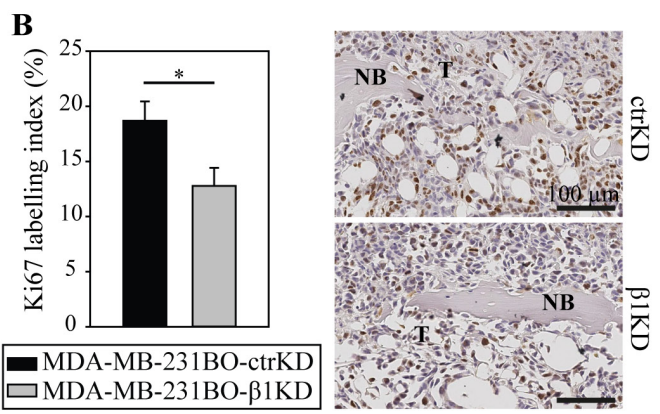

C

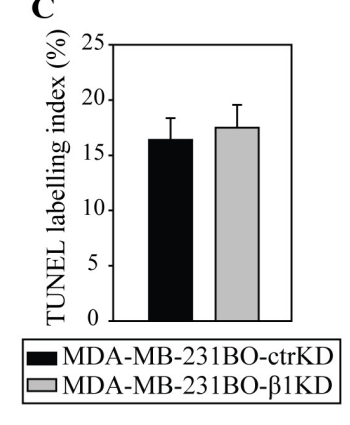

D
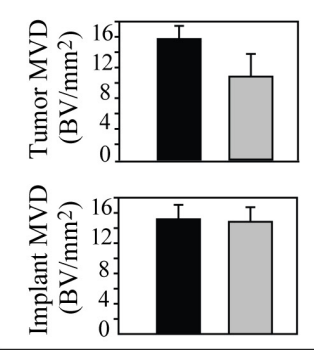
$\square$ MDA-MB-231BO-ctrKD
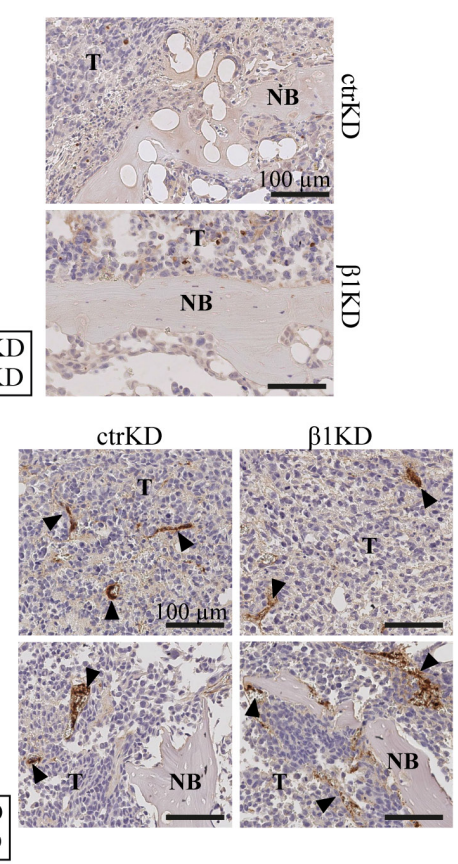

Figure 4: $\beta 1$ integrins promote tumor growth in bone by increasing cell proliferation in vivo. A: Analysis and representative images of H\&E-stained tumor/hTEBC samples. Overviews and magnified images are shown (dotted line: boundaries of the hTEBCs). Detection of human-specific NuMA by IHC demonstrates the human origin of the cancer cells and osteoblasts. B: IHC detection of cell proliferation using the human-specific Ki67 marker. C: IHC analysis of cell apoptosis using a TUNEL stain. D: IHC analysis of vascularization in the implant and tumor using the vWF marker. Data are represented as mean \pm standard error. BM: bone marrow, NB: new bone, T: tumor. 
micro-computed tomography ( $\mu-\mathrm{CT})$ analysis of the average mineralized tissue volume (BV), mineralized tissue volume fraction (BV/TV) and bone mineral density (BMD) were performed, but the differences were not statistically significant between groups (Figure 5A). Next, histomorphometric analyses were performed on histological sections of the samples but, consistent with the $\mu$-CT results, no differences in the amount of bone could be detected between the ctrKD and $\beta 1 \mathrm{KD}$ groups (Supplementary Figure 8). The bone in contact with the cancer cells had obvious osteolytic changes in the presence of tumors from both cell groups and the presence of osteoclasts in resorption pits along the bone surfaces was confirmed by tartrate-resistant acid phosphatase (TRAP) staining (Figure 5B). Cells positive for TRAP
- presumably macrophages - also were observed in the tumor not adjacent to bone (Supplementary Figure 8). Histomorphometric analyses were performed to quantify the number of multinucleated and TRAP-positive osteoclasts on the bone surface; however no significant differences in the average number of osteoclasts normalized to the mineralized tissue area (N.Oc/B.Ar) and perimeter (N.Oc/B.Pm) were observed in the presence of tumor cells from the ctrKD or $\beta 1 \mathrm{KD}$ group (Figure 5B). This is consistent with qRT-PCR results, which did not detect a significant difference in the gene expression of the osteoclastic factors parathyroid hormone-related protein (PTHrP), osteoprotegerin (OPG), interleukin 6 (IL-6) and receptor activator of nuclear factor kappa-B ligand (RANKL) when $\beta 1$ integrins were decreased (Figure 5C).

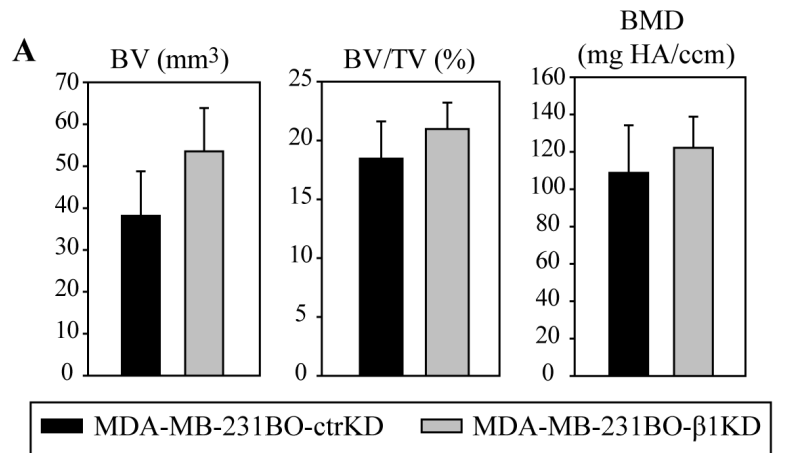

B
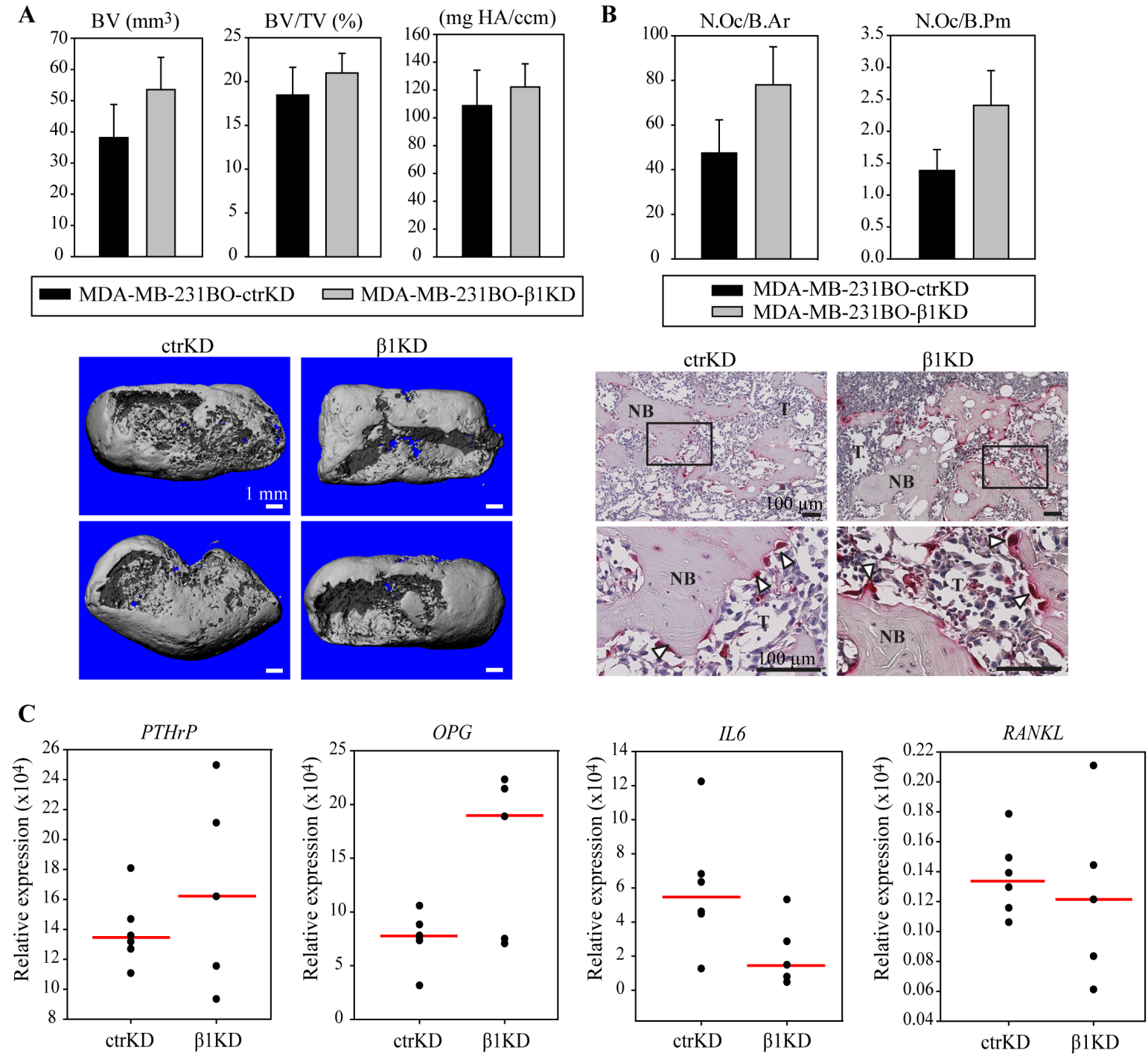

Figure 5: $\beta 1$ integrins do not influence $\mathrm{BC}$-induced bone resorption and osteoclast activation in vivo. A: Representative $3 \mathrm{D}$ reconstructions of $\mu-\mathrm{CT}$ data and quantification of BV, BV/TV and BMD. B: Histomorphometric analysis of osteoclast density normalized to the mineralized tissue area (N.Oc/B.Ar) or perimeter (N.Oc/B.Pm) and representative images of TRAP staining at low and high magnification. C: qRT-PCR analysis of PTHrP, OPG, IL-6 and RANKL gene expression in tumors formed in hTEBCs. Data in bar charts are represented as mean \pm standard error. Dot plots represent individual data points and median. NB: new bone, T: tumor. 


\section{Tumor-harboring hTEBCs mimic closely clinical bone metastases from $\mathrm{BC}$ patients}

In order to correlate the observations made in our in vivo model with the clinic, we next compared histological sections of tumor-injected hTEBCs and clinical specimens of bone metastases. The latter consisted of tissue microarrays assembled from bone metastases from a cohort of 22 patients with breast carcinoma. H\&E stainings revealed that bone metastases generated in the engineered bone bore a great resemblance to the clinical specimens (Figure 6A). In both cases, the cancer cells invaded the hematopoietic niche and were intermingled with other cell types such as adipocytes or hematopoietic cells (Figure $6 \mathrm{~A}$, left panel). The tumors invaded all the inter-trabecular spaces, gradually replacing the bone marrow and inducing the break-down of the bone matrix (Figure 6A, middle and right panels).
Our in vivo experiments are based on the use of the triple negative MDA-MB-231BO cell line which expresses high levels of $\beta 1$ integrins compared to other $\mathrm{BC}$ cell lines [27], whereas patient tumors may exhibit varied molecular profiles depending on their subtype or histopathological grading. Thus, we next analyzed $\beta 1$ integrin expression in the clinical tissue specimens. $\beta 1$ integrin expression was detected in most cases using IHC, although staining intensity varied significantly across patient samples, with 5 cases showing moderate-to-strong immunoreactivity while other cases had a more diffuse cytoplasmic positive staining. Although variable $\beta 1$ integrin expression levels were observed in the clinical specimens, $\beta 1$ integrins could be detected in bone metastases of different subtypes of breast carcinoma and with different grading and hormone receptor status (Figure 6B).

A
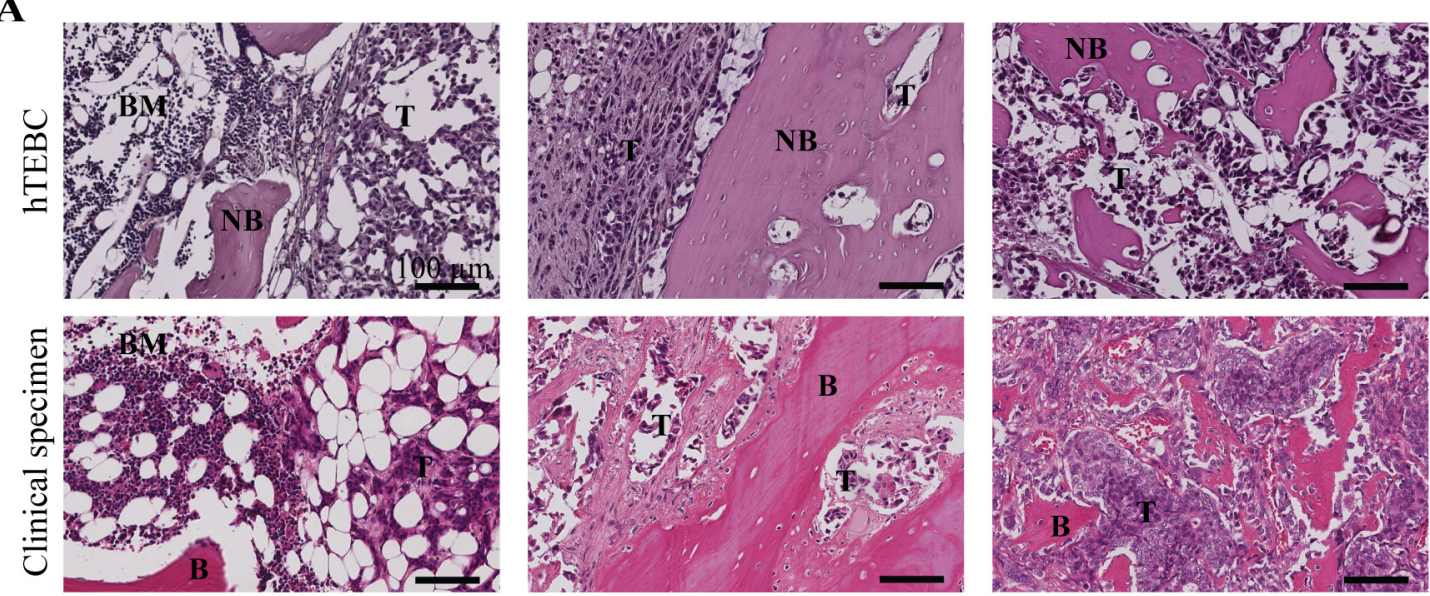

B
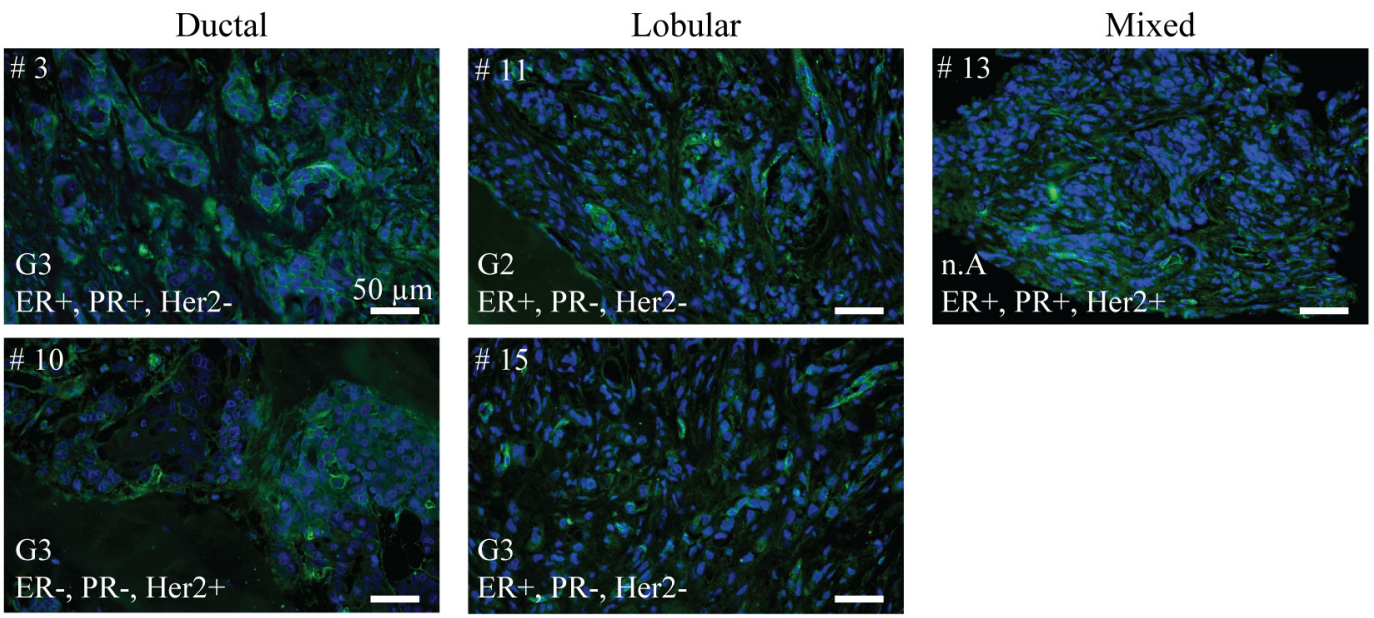

Figure 6: Tumor development in the hTEBC is representative of clinical bone metastases from breast carcinoma patients. A: Representative H\&E images showing the similarity between the tumor-harboring hTEBCs and clinical specimens at the histological level. B: IHC stainings of $\beta 1$ integrin expression in bone metastases from patients with ductal, lobular or mixed mammary carcinoma. $\beta 1$ integrins are labelled with Alexa Fluor 488 dye (green) and nuclei counterstained with DAPI (blue). Patient case number (\#), histopathological grading score (G), and hormone receptor status (ER/PR/HER2: estrogen/progesterone/human epidermal growth factor receptor) for the bone metastases are shown. BM: bone marrow, NB: new bone, B: bone, T: tumor. 


\section{DISCUSSION}

The critical roles of integrins in $\mathrm{BC}$ metastasis to bone have been widely described in the literature [10, 11], and these cell adhesion receptors are considered a promising target for developing new treatment strategies. In particular, $\beta 1$ and $\beta 3$ integrins have both been shown to promote osteotropic metastasis; however, whether they predominantly mediate tumor cell dissemination to, or colonization of the distant bone site by $\mathrm{BC}$ cells is not fully understood. To date, only $\alpha v \beta 3$ integrins have been specifically studied in the context of $\mathrm{BC}$-induced bone colonization. In this study, we investigated the specific role of $\beta 1$ integrins in bone colonization by metastatic $\mathrm{BC}$ cells using our recently developed in vitro and in vivo humanized bone models.

We firstly observed that $\mathrm{BC}$ cells with reduced $\beta 1$ expression adopted a more rounded morphology on the hOBM. This has been observed previously for mouse mammary cancer cells expressing shRNA targeting $\beta 1$ integrin expression when they were cultured on basement membrane extract and collagen type I [37]. Additionally, in this study, $\beta 1 \mathrm{KD}$ cells adhered significantly less to bone ECM (hOBM) than controls. This is in accordance with our previous results which showed a decrease of BC cell adhesion to hOBM in the presence of a $\beta 1$ integrin function-blocking antibody [27]. Similarly, it has been previously demonstrated that $\beta 1, \alpha 1, \alpha 2$, and $\alpha 3$ integrin neutralizing antibodies strongly inhibited adhesion of $\mathrm{BC}$ cells to type I collagen or bovine cortical bone chips [28, 29]. In another study, pre-treatment of $B C$ cells with snake venom disintegrins, such as rhodostomin, trigramin, and triflavin, reported to interfere with the function of $\alpha \operatorname{IIb} \beta 3$, $\alpha 5 \beta 1$ and $\alpha v \beta 3$ integrins, inhibited adhesion of tumor cells to unmineralized and mineralized cell-secreted matrices produced by either MG-63 cells osteosarcoma cells or differentiated osteoblasts [22]. Furthermore, it has been shown that $\alpha v \beta 3$ overexpression does not increase tumor cell adhesion to bone matrix proteins [19] and that blocking $\alpha v \beta 3$ does not affect cells attachment to hOBM or bovine bone chips [27, 28]. Overall, these findings indicate that $\beta 1$ integrins mediate $\mathrm{BC}$ cell adhesion to bone matrix proteins, and there are clues that $\beta 3$ integrins may only play a minor role.

Using transwell assays, it has been shown before that disintegrins with selectivity for both $\beta 1[22,38]$ and $\beta 3$ integrins $[21,22]$ inhibit chemotactic migration of $B C$ cells toward ECM proteins, conditioned media or serum. In this study, we further observed that perturbed $\beta 1$ integrin expression reduced the ability of $\mathrm{BC}$ cells to migrate along the hOB-secreted ECM fibers in the hOBM. This is consistent with previous reports showing $\beta 1$ integrindependent directional migration of $\mathrm{BC}$ cells within $3 \mathrm{D}$ fibroblast-secreted ECM matrices [39], which was mainly attributed to $\beta 1$ integrin binding to fibronectin fibers that are abundantly present in fibroblast-, but also our hOB- secreted matrices. We subsequently investigated the effect of $\beta 1$ knockdown on cell proliferation and the regulation of ERK $1 / 2$ and FAK signaling pathways. $\beta 1$ integrins did not influence BC cell proliferation in either TCP, hOBM or 3D hydrogels. Moreover, no effect on ERK and FAK phosphorylation levels was observed. Similar results have been obtained before on two-dimensional surfaces after knockdown of $\beta 1$ integrins [40]. However, our results in 3D hydrogels are in contrast to previous studies, which demonstrated a significant decrease in proliferation in 3D ECM gels after disruption of the $\beta 1$ integrin-FAK signaling axis in tumor cells $[14,40]$. This discrepancy could be explained by the use of laminin-rich hydrogels to culture the $\mathrm{BC}$ cells, as opposed to the gelatin-based hydrogels used in our work. Since integrin downstream signaling pathways are also regulated by other integrin subunits and receptors, it is conceivable that the effect of $\beta 1$ knockdown on downstream targets is highly substrate and cell type specific.

In order to investigate the role of $\beta 1$ integrins on bone colonization in vivo, we next assessed tumor development after injection of metastatic $\mathrm{BC}$ cells into an ectopic humanized bone ossicle. In contrast to the in vitro result, $\beta 1$ knockdown had a significant effect on tumor development in bone in vivo. FAK is known to integrate integrin and growth factor signaling [36], which may explain the different effects of $\beta 1$ knockdown in vitro and in vivo, where the activation of both signaling axes is expected to be very different from each other. The reduction of $\beta 1$ integrin expression in $\mathrm{BC}$ cells resulted in a delayed and reduced tumor growth in the hTEBCs, although tumor development was not prevented. Analysis by quantitative IHC revealed that the differences in tumor size within the humanized bone ossicle were related to a decreased proliferative potential in $\beta 1 \mathrm{KD}$ cells compared to ctrKD, while no differences in cell apoptosis and tumor vascularization were observed. This result is consistent with a recent study, which showed that loss of $\beta 1$ integrins in PyVmT-induced mammary tumors in transgenic mice inhibited the proliferative capacity of tumor cells, but did not contribute to apoptotic cell death [12,13]. Moreover the use of a specific inhibitory antibody against $\beta 1$ integrins (AIIB2) also resulted in decreased mammary tumor formation [14]. Next to a decreased proliferative potential, another mechanism likely to play a role in the reduced tumor growth observed in the $\beta 1 \mathrm{KD}$ group is the impaired initial adhesion of the tumor cells to the ECM of the humanized bone. Although cell attachment to the bone matrix could not be quantified in vivo, this hypothesis is consistent with our in vitro results and with the observed initial delay in tumor development after injection, which suggests that $\beta 1$ integrins may play a predominant role early in the bone colonization process. Only few studies so far have investigated the role of integrins during $\mathrm{BC}$ cell proliferation in the bone microenvironment in vivo. MDA-MB-231 BC cell proliferation in the tibia of nude 
mice was markedly inhibited using trigramin, a snake venom-derived disintegrin which binds to $\alpha \mathrm{II} \beta 3, \alpha v \beta 3$ and $\alpha 5 \beta 1$ [22]. Similar to the studies with integrinblocking antibodies, this approach does not target a specific integrin subunit and can influence other integrin $\beta 1$ and $\beta 3$-expressing cell types such as endothelial cells or osteoclasts. However, it has been shown that $\alpha v \beta 3$ overexpression does not affect $66 \mathrm{cl} 4$ cell proliferation in mouse tibia [19], thus indicating that this family of adhesion receptors is not critical for $\mathrm{BC}$ cell proliferation in bone. Thus, to our knowledge, we show here for the first time that $\beta 1$ integrins expressed on BC cells play a significant role in the regulation of tumor growth in bone in vivo.

Despite decreased tumor size in animals injected with $\beta 1 \mathrm{KD}$ cells, we did not observe any significant differences in bone resorption and osteoclast activation between groups. This result indicates that $\beta 1$ integrins do not play a major role in the induction of osteolytic lesion by metastatic BC cells. It also underlines the fact that an increased ability of $\mathrm{BC}$ cells to promote tumor expansion in the bone microenvironment does not necessarily correlate with an increased ability to recruit osteoclasts and promote bone resorption, as it has been shown before [19]. Since other studies have seen effects of $\alpha v \beta 3$ integrin inhibitors on osteolytic lesions [21, 22], this may suggest that possibly $\alpha v \beta 3$ integrins may be more important in osteolysis. However, the employed integrin inhibitors act not only on BC cells, but also on osteoclasts. Thus the effect of $\alpha v \beta 3$ inhibitors on osteolytic activity may be predominantly due to the inhibition of $\beta 3$ integrins on osteoclasts, which are critical in osteoclast-mediated bone resorption [41]. For instance, the $\alpha v \beta 3$ inhibitor S247 was shown to induce significant morphological changes and impair formation of the actin sealing zone in osteoclast cultures [23].

In conclusion, using engineered human-bone mimicking in vitro and in vivo models we were able to delineate specific roles for tumor $\beta 1$ integrins in the colonization of bone by metastatic BC cells. We have shown that $\beta 1$ integrins promote the adhesion and migration of $\mathrm{BC}$ cells within bone matrix in vitro and promote tumor growth in bone in vivo. Using IHC analysis on a tissue micro-array assembled from a cohort of 22 patients we have shown that $\beta 1$ integrins are detected in clinical bone metastatic tissue across different BC subtypes, although expression levels vary considerably between specimens. To date, three $\beta 1$ integrin inhibitors (ATN-161, volociximab, and JSM6427) have been tested in clinical trials and show some promising results in the inhibition of tumor growth and distant metastasis in patients with solid tumors [42]. The new mechanistic insights of our study underline the potential of $\beta 1$ integrins as a therapeutic target to limit tumor initiation and expansion in patients with bone metastases. Since not only $\mathrm{BC}$ growth, but also an inhibition of the bone-destructive action induced by $\mathrm{BC}$ cells is of great therapeutic relevance, the use of combination therapies with other inhibitors (i.e. against $\beta 3$ integrins) may be necessary to efficiently target $\mathrm{BC}$ bone colonization and ultimately improve patient outcomes.

\section{MATERIALS AND METHODS}

\section{Cell lines}

Bone-metastatic BC cell lines SUM1315, MDAMB-231, and MDA-MB-231BO were utilized in this study. MDA-MB-231 cells were purchased from the American Type Culture Collection (Manassas, Virginia, USA). MDA-MB-231BO cells were kindly provided by the University of Texas Health Science Center at San Antonio (San Antonio, Texas, USA) and SUM1315 cells were a gift from David Kaplan from the Tufts University (Medford, Massachusetts, USA). MDA-MB-231 and MDA-MB-231BO cells were maintained in high glucose Dulbecco's Modified Eagle Medium supplemented with $10 \%$ fetal bovine serum (FBS), $100 \mathrm{U} / \mathrm{mL}$ penicillin, $100 \mu \mathrm{g} / \mathrm{mL}$ streptomycin and 1x Glutamax, all sourced from Life Technologies (Mulgrave, Victoria, Australia). SUM1315 cells were cultured in F12 medium (Life Technologies) supplemented with $5 \mu \mathrm{g} / \mathrm{mL}$ human insulin (Sigma-Aldrich, St. Louis, Missouri, USA), $10 \mathrm{ng} / \mathrm{mL}$ epidermal growth factor (Sigma-Aldrich), 10\% FBS and penicillin/ streptomycin. BC cell lines were modified by retroviral transduction to stably express shRNA targeting integrin $\beta 1$ RNA ( $\beta 1 \mathrm{KD})$, while control cells (ctrKD) expressed shRNA specific for firefly luciferase-GL2 RNA, together with a GFP reporter. The virus particles were kindly provided by T. Kwok [43]. Knockdown of integrin $\beta 1$ was confirmed by qRT-PCR, flow cytometry, and immunoblotting (Supplementary Figure 1), as previously described [27].

\section{Preparation of hOBM}

hOBs were isolated from bone tissue obtained under informed consent from female patients undergoing hip or knee replacement surgery (ethics approval number 0600000232), as described previously [26, 27]. hOBM for subsequent in vitro assays were prepared as previously described [26, 27]. Briefly, hOBs were seeded at a density of 3000 cells $/ \mathrm{cm}^{2}$ onto thermanox ${ }^{\mathrm{TM}}$ coverslips (Nunc, Thermo Fisher). Upon reaching confluency, cells were cultured under osteogenic conditions, in cell culture medium supplemented with $50 \mu \mathrm{g} / \mathrm{ml}$ ascorbate2-phosphate, $10 \mathrm{mM} \beta$-glycerophosphate, and $0.1 \mu \mathrm{M}$ dexamethasone (Sigma-Aldrich, Australia). After 4 weeks, mineralized matrices were decellularized using $20 \mathrm{mM}$ ammonium hydroxide following a previously described 
protocol $[26,27]$.

\section{In vivo hTEBC model}

All procedures were approved by the Queensland University of Technology Animal Ethics Committee (ethics approval number 0900000915) and carried out in accordance with the Australian Code of Practice for the Care and Use of Animals for Scientific Purposes. Fourweek old female NOD/SCID mice were purchased from the Animal Resources Centre (Canning Vale, Western Australia, Australia) and maintained under specific pathogen-free, temperature-controlled conditions at the Pharmacy Australia Centre of Excellence animal facility (University of Queensland, Queensland, Australia). Animal experiments were performed using our previously described hTEBC model [30-32]. Briefly, calcium phosphate-coated melt electrospun polycaprolactone scaffolds were seeded with hOBs and cultured in osteogenic differentiation media for 8 weeks. Constructs were implanted s.c. in the flanks of the animals in combination with recombinant human BMP-7 (Olympus Biotech Corporation, Hopkinton, MA) and fibrin glue (TISSEEL Fibrin Sealant, Baxter Healthcare International, Deerfield, IL). New bone was allowed to form for 14 weeks and monitored at 4-6 weeks intervals with X-ray radiography. One million $\mathrm{BC}$ cells were then injected transcutaneously into each construct ( $\mathrm{n}=7$ hTEBCs per group) and tumor development was monitored weekly by in vivo fluorescent imaging using a Xenogen IVIS Spectrum (PerkinElmer, Waltham, Massachusetts, USA). At the experimental endpoint, hTEBCs were excised and analyzed by ex vivo fluorescent imaging. Image acquisition and analysis was performed using the spectral unmixing mode in the Living Image software (PerkinElmer). Signals were quantified by drawing an automatic region of interest with a threshold set at $10 \%$ around each fluorescent signal. Only signals above 800 counts were considered positive, a value which is more conservative than the threshold recommended by the manufacturer. Gross tumor measurements were performed with calipers upon explantation. Then, tumor specimens were either snap frozen in liquid nitrogen and stored at $-80 \mathrm{C}$ before RNA extraction, or fixed in $4 \%$ paraformaldehyde overnight and then transferred to $70 \%$ ethanol for further analysis. In addition, ex vivo $\mu$-CT analysis was performed on fixed samples as previously described [30].

\section{Histology and immunohistochemistry}

Fixed samples were decalcified for 5 weeks in 10\% ethylenediaminetetraacetic acid ( $\mathrm{pH}$ 7.4) with weekly changes, and subsequently embedded in paraffin. Samples were stained routinely with $\mathrm{H} \& \mathrm{E}$ for morphological analysis of the tissue. To detect specific target proteins of interest, IHC was performed following a previously described protocol [30]. Primary antibodies used for IHC analysis are listed in Supplementary Table 1. Terminal deoxynucleotidyl transferase dUTP nick end labeling (TUNEL) staining was performed to detect apoptotic cells using a DeadEnd ${ }^{\mathrm{TM}}$ Colorimetric TUNEL System (Promega, Madison, WI, USA) according to the manufacturer's instructions. TRAP staining to detect osteoclasts was performed as previously described [30]. Sections were scanned at X20 magnification using a Leica SCN400 slide scanner (Leica Microsystems, Wetzlar, Germany) before image analysis.

\section{Image analysis}

To quantify histochemical and IHC stainings, at least five different samples (hTEBCs) were assessed per experimental group, with two sections each (one from the central region of the sample; one approximately separated by $150 \mu \mathrm{m}$ from the first section). The open source webbased ImmunoRatio application (Institute of Medical Technology, University of Tampere, Tampere, Finland) was used for automated image analysis of Ki67, GFP and TUNEL expression [44]. ImmunoRatio calculates a labeling index which corresponds to the percentage of diaminobenzidine-stained area over total hematoxylinstained area. To validate this method, ImmunoRatio analysis of the Ki67-stained sections was compared to the analysis using ImageJ (Supplementary Figure 7). Quantification of microvessel density (MVD) was performed by manual counting of von Willebrand factor (vWF)-positive blood vessels in the entire sections and numbers were normalized to the tissue area ("implant" and "tumor" outside implant were quantified separately). Histomorphometry analysis on TRAP-stained sections was performed using the Osteomeasure software (OsteoMetrics Inc., Atlanta, GA, USA) to quantify the number of osteoclasts per bone area and perimeter. Only multinucleated, TRAP-positive cells on the bone surface were considered osteoclasts. TRAP-positive cells in the tumor area were also counted separately and normalized to total tumor area.

\section{Statistical analysis}

Datasets were analyzed using the SigmaPlot software (Systat Software Inc, San Jose, California, USA). Normally distributed data was analyzed for statistical differences between groups using a Student t-test (2 groups) or a one-way ANOVA ( $>2$ groups). Data that failed the normality test was analyzed either using a Mann-Whitney test (2 groups) or a Kruskal-Wallis one-way ANOVA on ranks ( $>2$ groups). $\mathrm{P}<0.05$ was considered significant. 


\section{ACKNOWLEDGMENTS}

The work presented by the authors is supported by the Australian Research Council and the National Health and Medical Research Council. A.V.T. and B.M.H. are funded by the German Research Foundation [DFG HO 5068/1-1 to B.M.H.]. We would also like to acknowledge the funding support from the Pathology Queensland Study, Education and Research Trust Fund obtained in collaboration with O.R. Fibrin glue (TISSEEL Fibrin Sealant) was kindly provided by Baxter Healthcare International and BMP-7 was a generous gift from Olympus Biotech Corporation. MDA-MB-231BO cells were received by the University of Texas Health Science Center at San Antonio and SUM1315 cells from D. Kaplan from the Tufts University. Lentivirus particles were kindly provided by T. Kwok. We thank M. Goerdes, N. Benson for their technical assistance. We are grateful to T. Friis, S. Sieh for helpful advice on the PCR analysis.

\section{Disclosure}

The authors declare that they have no conflict of interest.

\section{REFERENCES}

1. Australian Institute of Health and Welfare. (2012). Breast cancer in Australia: an overview. . In: AIHW. C, ed. Cancer series no 71 (Canberra.

2. Ferlay J, Steliarova-Foucher E, Lortet-Tieulent J, Rosso S, Coebergh JW, Comber H, Forman D and Bray F. Cancer incidence and mortality patterns in Europe: estimates for 40 countries in 2012. Eur J Cancer. 2013; 49(6):1374-1403.

3. Siegel R, Ma J, Zou Z and Jemal A. Cancer statistics, 2014. CA: A Cancer Journal for Clinicians. 2014; 64(1):9-29.

4. Clines GA and Guise TA. Mechanisms and treatment for bone metastases. Clinical advances in hematology \& oncology : H\&O. 2004; 2(5):295-302.

5. Buijs JT and van der Pluijm G. Osteotropic cancers: from primary tumor to bone. Cancer Letters. 2009; 273(2):177193.

6. Yoneda T and Hiraga T. Crosstalk between cancer cells and bone microenvironment in bone metastasis. Biochemical and Biophysical Research Communications. 2005; 328(3):679-687.

7. Brooks SA, Lomax-Browne HJ, Carter TM, Kinch CE and Hall DMS. Molecular interactions in cancer cell metastasis. Acta Histochemica. 2010; 112(1):3-25.

8. Desgrosellier JS and Cheresh DA. Integrins in cancer: biological implications and therapeutic opportunities. Nat Rev Cancer. 2010; 10(1):9-22.

9. Marelli UK, Rechenmacher F, Sobahi TR, Mas-Moruno $\mathrm{C}$ and Kessler H. Tumor targeting via integrin ligands.
Frontiers in oncology. 2013; 3:222.

10. Schneider JG, Amend SR and Weilbaecher KN. Integrins and bone metastasis: Integrating tumor cell and stromal cell interactions. Bone. 2011; 48(1):54-65.

11. White D and Muller W. Multifaceted roles of integrins in breast cancer metastasis. Journal of Mammary Gland Biology and Neoplasia. 2007; 12(2-3):135-142.

12. White DE, Kurpios NA, Zuo D, Hassell JA, Blaess S, Mueller $U$ and Muller WJ. Targeted disruption of $\beta 1$ integrin in a transgenic mouse model of human breast cancer reveals an essential role in mammary tumor induction. Cancer cell. 2004; 6(2):159-170.

13. Lahlou $\mathrm{H}$ and Muller $\mathrm{W}$. beta1-integrins signaling and mammary tumor progression in transgenic mouse models: implications for human breast cancer. Breast Cancer Research. 2011; 13(6):229.

14. Park CC, Zhang H, Pallavicini M, Gray JW, Baehner F, Park CJ and Bissell MJ. $\beta 1$ integrin inhibitory antibody induces apoptosis of breast cancer cells, inhibits growth, and distinguishes malignant from normal phenotype in three dimensional cultures and in vivo. Cancer Research. 2006; 66(3):1526-1535.

15. Huck L, Pontier SM, Zuo DM and Muller WJ. beta1integrin is dispensable for the induction of ErbB2 mammary tumors but plays a critical role in the metastatic phase of tumor progression. Proc Natl Acad Sci U S A. 2010; 107(35):15559-15564.

16. Elliott BE, Ekblom P, Pross H, Niemann A and Rubin K. Anti-beta 1 integrin IgG inhibits pulmonary macrometastasis and the size of micrometastases from a murine mammary carcinoma. Cell Adhes Commun. 1994; 1(4):319-332.

17. Khalili P, Arakelian A, Chen G, Plunkett ML, Beck I, Parry GC, Donate F, Shaw DE, Mazar AP and Rabbani SA. A non-RGD-based integrin binding peptide (ATN-161) blocks breast cancer growth and metastasis in vivo. Mol Cancer Ther. 2006; 5(9):2271-2280.

18. Felding-Habermann B, O'Toole TE, Smith JW, Fransvea E, Ruggeri ZM, Ginsberg MH, Hughes PE, Pampori N, Shattil SJ, Saven A and Mueller BM. Integrin activation controls metastasis in human breast cancer. Proceedings of the National Academy of Sciences. 2001; 98(4):1853-1858.

19. Sloan E, Pouliot N, Stanley K, Chia J, Moseley J, Hards D and Anderson R. Tumor-specific expression of alphavbeta3 integrin promotes spontaneous metastasis of breast cancer to bone. Breast Cancer Research. 2006; 8(2):R20.

20. Zhao Y, Bachelier R, Treilleux I, Pujuguet P, Peyruchaud $\mathrm{O}$, Baron R, Clement-Lacroix P and Clezardin P. Tumor alphavbeta3 integrin is a therapeutic target for breast cancer bone metastases. Cancer Res. 2007; 67(12):5821-5830.

21. Bretschi M, Merz M, Komljenovic D, Berger MR, Semmler W and Bauerle T. Cilengitide inhibits metastatic bone colonization in a nude rat model. Oncol Rep. 2011; 26(4):843-851. 
22. Yang R-S, Tang C-H, Chuang W-J, Huang T-H, Peng H-C, Huang T-F and Fu W-M. Inhibition of tumor formation by snake venom disintegrin. Toxicon. 2005; 45(5):661-669.

23. Harms J, Welch D, Samant R, Shevde L, Miele M, Babu G, Goldberg S, Gilman V, Sosnowski D, Campo D, Gay C, Budgeon L, Mercer R, Jewell J, Mastro A, Donahue $\mathrm{H}$, et al. A small molecule antagonist of the $\alpha v \beta 3$ integrin suppresses MDA-MB-435 skeletal metastasis. Clinical and Experimental Metastasis. 2004; 21(2):119-128.

24. Yao ES, Zhang H, Chen YY, Lee B, Chew K, Moore D and Park C. Increased betal integrin is associated with decreased survival in invasive breast cancer. Cancer Res. 2007; 67(2):659-664.

25. dos Santos PB, Zanetti JS, Ribeiro-Silva A and Beltrao EI. Beta 1 integrin predicts survival in breast cancer: a clinicopathological and immunohistochemical study. Diagnostic pathology. 2012; 7:104.

26. Reichert JC, Quent VMC, Burke LJ, Stansfield SH, Clements JA and Hutmacher DW. Mineralized human primary osteoblast matrices as a model system to analyse interactions of prostate cancer cells with the bone microenvironment. Biomaterials. 2010; 31(31):7928-7936.

27. Taubenberger AV, Quent VM, Thibaudeau L, Clements JA and Hutmacher DW. Delineating breast cancer cell interactions with engineered bone microenvironments. J Bone Miner Res. 2013; 28(6):1399-1411.

28. Lundstrom A, Holmbom J, Lindqvist C and Nordstrom T. The role of alpha 2 beta 1 and alpha3 beta1 integrin receptors in the initial anchoring of MDA-MB-231 human breast cancer cells to cortical bone matrix. Biochem Biophys Res Commun. 1998; 250(3):735-740.

29. Ibaragi S, Shimo T, Hassan NMM, Isowa S, Kurio N, Mandai H, Kodama S and Sasaki A. Induction of MMP13 expression in bone-metastasizing cancer cells by type I collagen through integrin $\alpha 1 \beta 1$ and $\alpha 2 \beta 1-p 38$ MAPK signaling. Anticancer Res. 2011; 31(4):1307-1313.

30. Thibaudeau L, Taubenberger AV, Holzapfel BM, Quent VM, Fuehrmann T, Hesami P, Brown TD, Dalton PD, Power CA, Hollier BG and Hutmacher DW. A tissueengineered humanized xenograft model of human breast cancer metastasis to bone. Disease Models \& Mechanisms. 2014; 7(2):299-309.

31. Hesami P, Holzapfel BM, Taubenberger A, Roudier M, Fazli L, Sieh S, Thibaudeau L, Gregory LS, Hutmacher DW and Clements JA. A humanized tissue-engineered in vivo model to dissect interactions between human prostate cancer cells and human bone. Clin Exp Metastasis. 2014.

32. Holzapfel BM, Wagner F, Loessner D, Holzapfel NP, Thibaudeau L, Crawford R, Ling M-T, Clements JA, Russell PJ and Hutmacher DW. Species-specific homing mechanisms of human prostate cancer metastasis in tissue engineered bone. Biomaterials. 2014.

33. Yoneda $\mathrm{T}$, Williams PJ, Hiraga $\mathrm{T}$, Niewolna $\mathrm{M}$ and Nishimura R. A bone-seeking clone exhibits different biological properties from the MDA-MB-231 parental human breast cancer cells and a brain-seeking clone in vivo and in vitro. Journal of Bone and Mineral Research. 2001; 16(8):1486-1495.

34. Sieg DJ, Hauck CR, Ilic D, Klingbeil CK, Schaefer E, Damsky CH and Schlaepfer DD. FAK integrates growthfactor and integrin signals to promote cell migration. Nat Cell Biol. 2000; 2(5):249-256.

35. Chen H, Zhu G, Li Y, Padia RN, Dong Z, Pan ZK, Liu $\mathrm{K}$ and Huang S. Extracellular signal-regulated kinase signaling pathway regulates breast cancer cell migration by maintaining slug expression. Cancer Research. 2009; 69(24):9228-9235.

36. Provenzano PP, Inman DR, Eliceiri KW and Keely PJ. Matrix density-induced mechanoregulation of breast cell phenotype, signaling and gene expression through a FAKERK linkage. Oncogene. 2009; 28(49):4326-4343.

37. Barkan D, El Touny LH, Michalowski AM, Smith JA, Chu I, Davis AS, Webster JD, Hoover S, Simpson RM, Gauldie $\mathrm{J}$ and Green JE. Metastatic growth from dormant cells induced by a col-I-enriched fibrotic environment. Cancer Res. 2010; 70(14):5706-5716.

38. Kusuma N, Denoyer D, Eble JA, Redvers RP, Parker BS, Pelzer R, Anderson RL and Pouliot N. Integrin-dependent response to laminin-511 regulates breast tumor cell invasion and metastasis. Int J Cancer. 2012; 130(3):555-566.

39. Castello-Cros R, Khan D, Simons J, Valianou M and Cukierman E. Staged stromal extracellular 3D matrices differentially regulate breast cancer cell responses through PI3K and beta1-integrins. BMC Cancer. 2009; 9(1):94.

40. Shibue $T$ and Weinberg RA. Integrin beta1-focal adhesion kinase signaling directs the proliferation of metastatic cancer cells disseminated in the lungs. Proc Natl Acad Sci U S A. 2009; 106(25):10290-10295.

41. Nakamura I, Pilkington MF, Lakkakorpi PT, Lipfert L, Sims SM, Dixon SJ, Rodan GA and Duong LT. Role of alpha(v) beta(3) integrin in osteoclast migration and formation of the sealing zone. J Cell Sci. 1999; 112(Pt 22):3985-3993.

42. Barkan D and Chambers AF. $\beta 1$-integrin: a potential therapeutic target in the battle against cancer recurrence. Clinical Cancer Research. 2011; 17(23):7219-7223.

43. Kwok T, Zabler D, Urman S, Rohde M, Hartig R, Wessler S, Misselwitz R, Berger J, Sewald N, Konig W and Backert S. Helicobacter exploits integrin for type IV secretion and kinase activation. Nature. 2007; 449(7164):862-866.

44. Tuominen VJ, Ruotoistenmaki S, Viitanen A, Jumppanen $\mathrm{M}$ and Isola J. ImmunoRatio: a publicly available web application for quantitative image analysis of estrogen receptor (ER), progesterone receptor (PR), and Ki-67. Breast Cancer Res. 2010; 12(4):27. 